\title{
Identification of a role for Saccharomyces cerevisiae Cgr1p in pre-rRNA processing and 605 ribosome subunit synthesis
}

\author{
Terence I. Moy, ${ }^{2}$ Douglas Boettner, ${ }^{1}$ Judith C. Rhodes, ${ }^{1}$ Pamela A. Silver ${ }^{2}$ \\ and David S. Askew ${ }^{1}$
}

Author for correspondence: David S. Askew. Tel: +1 513558 2395. Fax: +1 5135582141. e-mail: David.Askew@uc.edu

\footnotetext{
1 University of Cincinnati College of Medicine, Department of Pathology \& Laboratory Medicine, Cincinnati, OH 45267-0529, USA

2 Department of Biological Chemistry and Molecular Pharmacology, Harvard Medical School and Department of Cancer Biology, Dana-Farber Cancer Institute, Boston, MA 02115, USA
}

\begin{abstract}
Saccharomyces cerevisiae CGR1 encodes a conserved fungal protein that localizes to the nucleolus. To determine if this localization reflects a role for Cgr1p in ribosome biogenesis two yeast cgr1 mutants were examined for defects in ribosome synthesis: a conditional depletion strain in which CGR1 is under the control of a tetracycline-repressible promoter and a mutant strain in which a C-terminal truncated Cgr1p is expressed. Both strains had impaired growth rates and were hypersensitive to the aminoglycosides paromomycin and hygromycin. Polysome analyses of the mutants revealed increased levels of free 405 subunits relative to 605 subunits, a decrease in 805 monosomes and accumulation of half-mer polysomes. Pulse-chase labelling demonstrated that pre-rRNA processing was defective in the mutants, resulting in accumulation of the 35S, 275 and 75 pre-rRNAs and delayed production of the mature $25 S$ and 5.8S rRNAs. The synthesis of the 185 and 5S rRNAs was unaffected. Loss of Cgr1 function also caused a partial delocalization of the 5'-ITS1 RNA and the nucleolar protein Nop1p into the nucleoplasm, suggesting that Cgr1p contributes to compartmentalization of nucleolar constituents. Together these findings establish a role for Cgr1p in ribosome biogenesis.
\end{abstract}

Keywords: yeast, nucleolus, ribosome biogenesis

\section{INTRODUCTION}

Ribosome synthesis plays an essential role in the cellular adaptation to nutrient availability in all micro-organisms, allowing for the tight coordination of protein synthetic capacity with the demand for rapid growth (reviewed in Planta, 1997; Warner, 1999; Nomura, 1999). In eukaryotic organisms, ribosome synthesis takes place primarily in the nucleolus, a specialized compartment of the nucleus that is responsible for the transcription of the rDNA genes, the processing of prerRNA and the coordinated assembly of pre-rRNAs with ribosomal proteins (reviewed by Scheer \& Weisenberger, 1994; Shaw \& Jordan, 1995; Venema \& Tollervey, 1999). Most of our understanding of eukaryotic ribosome synthesis has been obtained from the model yeast Saccharomyces cerevisiae (reviewed by Planta, 1997; Warner, 1999; Nomura, 1999). The yeast rDNA is transcribed by RNA polymerase I as a single

Abbreviations: ETS, external transcribed spacer; ITS, internal transcribed spacer.
$35 \mathrm{~S}$ precursor RNA that is processed into three mature rRNAs (reviewed by Warner, 1982; Raué \& Planta, 1991; Venema \& Tollervey, 1999). The 35 S pre-rRNA is flanked by two external transcribed spacers (ETSs), $5^{\prime}$ ETS and 3'-ETS, and contains two internal transcribed spacers (ITSs), ITS1 and ITS2, that separate the sequences for the three mature rRNAs: $18 \mathrm{~S}, 5 \cdot 8 \mathrm{~S}$ and $25 \mathrm{~S}$ (see Fig. 1). The mature 5.8S and $25 \mathrm{~S}$ rRNAs become incorporated into the $60 \mathrm{~S}$ ribosome, and the mature $18 \mathrm{~S}$ rRNA becomes part of the $40 \mathrm{~S}$ ribosome. A fourth rRNA (5S) is transcribed independently by RNA polymerase III from a separate transcription unit and this RNA is incorporated into the 605 ribosome. The removal of the spacer sequences from the pre-rRNAs, and the final maturation of the rRNAs, is a complex process that involves a number of non-ribosomal proteins and small nucleolar RNAs (Raué \& Planta, 1991; Kressler et al., 1999).

Since ribosome synthesis is tightly linked to growth, the ability to target nucleolar proteins involved in ribosome biogenesis would be an effective therapeutic strategy against fungal infections. However, the ability to design 


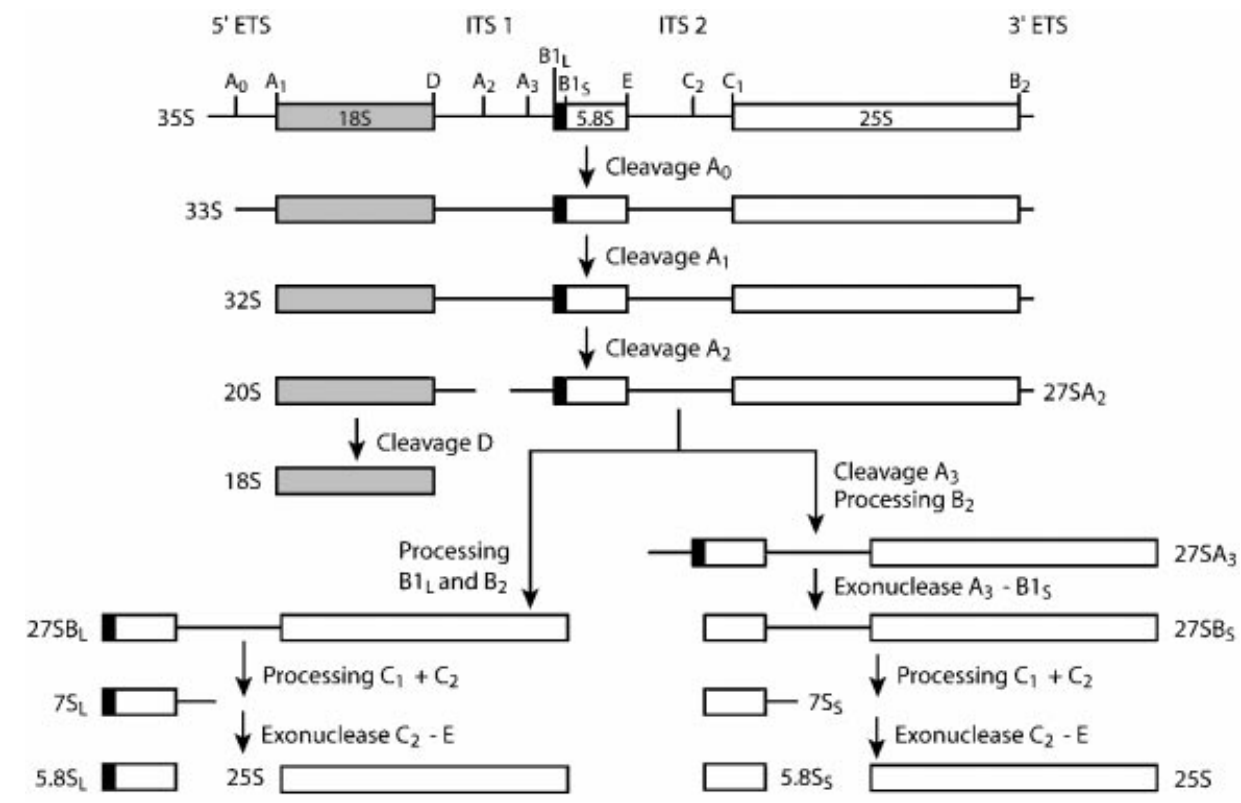

Fig. 1. The major pre-rRNA processing pathways in S. cerevisiae. The $35 \mathrm{~S}$ pre-rRNA is transcribed in the nucleolus and processed into the mature $18 \mathrm{~S}, 5.8 \mathrm{~S}$ and $25 \mathrm{~S}$ rRNAs by a series of endonucleolytic and exonucleolytic steps. The $35 \mathrm{~S}$ prerRNA is cleaved at site $A_{0}$ to generate the $33 S$ pre-rRNA and site $A_{1}$ to generate the 32S pre-rRNA. The 32S pre-rRNA is then cleaved at $A_{2}$ to produce the $20 \mathrm{~S}$ and $27 S A_{2}$ pre-rRNAs, thereby separating the RNAs destined for the small and large ribosomal subunits. Final maturation of the $20 \mathrm{~S}$ precursor into the $18 \mathrm{~S}$ rRNA occurs in the cytoplasm. The $27 \mathrm{SA} \mathrm{A}_{2}$ precursor is processed by one of two alternative pathways into the mature 5.8S and 25S rRNAs. These pathways are distinguished by the synthesis of either a long or short version of the 5.8S rRNA (the long version is indicated by the black box). The $27 \mathrm{~S}$ precursors of both pathways are eventually processed at sites $C 1$ and $C 2$ to yield the $7 S$ pre-rRNA and the mature $25 \mathrm{~S}$ rRNA. Subsequent $3^{\prime} \rightarrow 5^{\prime}$ exonucleolytic digestion of the $7 \mathrm{~S}$ rRNA generates the mature 5.8S rRNA. Figure modified with permission from Hong et al. (1997).

selective inhibitors of fungal ribosome synthesis is limited by insufficient knowledge of the proteins involved in ribosome biogenesis in pathogenic fungi. We have previously identified a yeast nucleolar protein, Cgr1p, that is highly conserved among fungi. Species homologues have been cloned from $S$. cerevisiae (Sun et al., 2001a), Aspergillus nidulans (Sun et al., 2001b) and Aspergillus fumigatus (Boettner et al., 2001), and putative homologues can be identified in the Neurospora crassa, Candida albicans and Schizosaccharomyces pombe databases. The A. fumigatus gene complemented a S. cerevisiae cgr1 mutant (Boettner et al., 2001), suggesting that the two genes encode orthologous proteins with overlapping functions. The goal of this study was to use $S$. cerevisiae as a model to determine whether this function involves ribosome synthesis. Here we demonstrate that $S$. cerevisiae Cgr1p is involved in the processing of the pre-rRNA for the $60 \mathrm{~S}$ ribosome subunit, thus establishing its role in ribosome synthesis and providing a foundation for future studies into ribosome synthesis as a potential drug target in $A$. fumigatus.

\section{METHODS}

Strains and culture conditions. The yeast strains used in this study are listed in Table 1 . Yeasts were grown on either rich medium [YPD : 1\% (w/v) yeast extract, $2 \%(\mathrm{w} / \mathrm{v})$ peptone,
$2 \%(\mathrm{w} / \mathrm{v})$ dextrose], synthetic medium [SD: 0.67\% (w/v) yeast nitrogen base without amino acids, $2 \%(\mathrm{w} / \mathrm{v})$ dextrose] that was supplemented to meet auxotrophic requirements for each strain, or synthetic drop-out medium (Burke et al., 2000). Generation times were calculated from cultures that were maintained in exponential growth for at least $30 \mathrm{~h}$ by diluting whenever the $\mathrm{OD}_{600}$ reached $0 \cdot 7$. To measure antibiotic sensitivity, $1 \times 10^{7}$ exponentially growing cells were plated in a top agar overlay $[1 \%(\mathrm{w} / \mathrm{v})$ agarose in YPD] onto YPD plates. A $0.75 \mathrm{~cm}$ diameter glass filter disc was then placed on the surface of each plate (Brandel) and $10 \mu \mathrm{l}$ of a dilution of either paromomycin (Sigma) or hygromycin (Sigma) was spotted onto each disc. The plates were cultured for 4 days at $30{ }^{\circ} \mathrm{C}$ and the diameter of the zone of growth inhibition around each filter was used as a measure of drug sensitivity.

Plasmids. A tetracycline-repressible CGR 1 expression plasmid was constructed by amplifying the CGR1 ORF from yeast genomic DNA (strain YPH250) using the forward primer 5'CGATGGATCCAGGAATATGGTGAATGAAACAGGAG-3' and the reverse primer 5'-CGATATCGATCTAACGTTCTTTTAAAGCC-3' (restriction sites are in italic). The PCR product was cloned into the pCM183 plasmid (Gari et al., 1997) at the BamHI and ClaI sites of the polylinker to make pDA361 (Table 1). This construction placed the CGR1 ORF downstream of a hybrid promoter comprising two copies of the tet operator sequence linked to the CYC1 promoter, and upstream of the CYC1 terminator.

Gel electrophoresis and blotting. For analysis of gene expression, RNA was isolated from yeast cultures by disruption with $0.5 \mathrm{~mm}$ glass beads (Fisher Scientific) according 
Cgr1p and ribosome synthesis

Table 1. Strains and plasmids

\begin{tabular}{|c|c|c|}
\hline $\begin{array}{l}\text { Strain or } \\
\text { plasmid }\end{array}$ & Genotype/construction & Source \\
\hline \multicolumn{3}{|l|}{ Strains } \\
\hline Cry1(Y300) & MAT a leu2-3,112 trp1-1 ura3-1 his3-11,15 can1-100 & $\begin{array}{l}\text { Y. Sanchez, University } \\
\text { of Cincinnati }\end{array}$ \\
\hline YDA110 & $\begin{array}{l}\text { MATa leu2-3,112 trp1-1 ura3-1 his3-11,15 can1-100 } \\
\text { cgr1 } \Delta 81-120: \text { kan }^{\mathrm{r}}\end{array}$ & This study \\
\hline YDA128 & $\begin{array}{l}\text { MAT a leu2-3,112 trp1-1 ura3-1 his3-11,15 can1-100 } \\
\text { cgr1s:: } \operatorname{kan}^{\mathrm{r}}(\mathrm{pDA} 361)\end{array}$ & This study \\
\hline \multicolumn{3}{|l|}{ Plasmids } \\
\hline pCM183 & $\mathrm{P}_{t e t O-C Y C 1}$ TRP1 CEN & ATCC \\
\hline pDA361 & pCM183, expressing S. cerevisiae CGR1 & This study \\
\hline
\end{tabular}

to standard procedures. Twenty micrograms of total RNA was fractionated by formaldehyde gel electrophoresis as previously described (Li et al., 1997), transferred to positively charged nylon membranes (MSI) and hybridized to ${ }^{32} \mathrm{P}-$ labelled DNA probes under stringent conditions in $50 \%(\mathrm{v} / \mathrm{v})$ formamide $/ 5 \times$ SSC $(1 \times$ SSC is $0 \cdot 15 \mathrm{M} \mathrm{NaCl}, 0 \cdot 015 \mathrm{M}$ sodium citrate, $\mathrm{pH} 7 \cdot 6$ ), $2 \times$ Denhardt's solution, $10 \%$ (w/v) dextran sulfate, $1 \%(\mathrm{w} / \mathrm{v})$ SDS. Hybridization intensity was quantified with a Phosphorimager (Molecular Dynamics) and normalized for loading by quantitating the relative levels of SYBR green (Molecular Probes) stained 18S rRNA on a Phosphorimager.

Genomic DNA was extracted by cell disruption in the presence of $0.5 \mathrm{~mm}$ diameter glass beads (Fisher Scientific) according to standard protocols. For genomic Southern blot analysis, $10 \mu \mathrm{g}$ digested DNA was fractionated on a $1 \%(\mathrm{w} / \mathrm{v})$ agarose gel, transferred to a nylon membrane (MSI) and hybridized to a $\left[{ }^{32} \mathrm{P}\right] \mathrm{dCTP}$-labelled probe under conditions of high stringency as previously described ( $\mathrm{Li}$ et al., 1997). Hybridization was monitored using a Phosphorimager (Molecular Dynamics).

Construction of a cgr1 truncation mutant and a cgr1 depletion mutant. A mutant expressing a C-terminal truncation of Cgr1p, YDA110, was constructed by one-step PCR-mediated gene disruption. The truncation cassette was obtained by PCR amplification of the kanamycin-resistance gene $\left(k a n^{\mathrm{r}}\right.$ ) using plasmid pFA6-3HA-kanMX6 (Wach et al., 1994) as the template and primers containing $50 \mathrm{bp}$ CGR1-homologous sequences. The upstream primer was 5'-GATGAGAAGGAAGAAGCTCGTCAAGCTAAAATAACCATGTTAAAGTGAGGCGCGCCACTTCTAAA-3' and the downstream primer was 5'-TATGAGCCTTCTATAATGCTTTATACCATTGTGCTTATCCGAATTCGAGCTCGTTTAAAC-3' (sequences in italic are specific to pFA6-3HA-kanMX6). This construction places a stop codon in place of amino acid 81 . The wild-type haploid yeast strain cry1 (Table 1) was transformed with the PCR product, selected on YPD plates containing $200 \mu \mathrm{g} \mathrm{G} 418 \mathrm{ml}^{-1}$ (Gibco-BRL) and the transformants were genotyped by PCR using a CGR1 primer outside the recombination site $\left(5^{\prime}\right.$-ATAACTGTCTAGGGATGCCC-3') and the $k a n^{r}$-specific primer (5'-ATCGGGCTTCCCATACAATC-3'). Confirmation of single-copy modification of CGR1 was obtained by genomic Southern blot analysis of EcoRI-digested genomic DNA using CGR1and $k a n^{r}$-specific probes.

To generate a conditional CGR1 depletion strain, the wildtype haploid strain cry1 was transformed with pDA361 and the chromosomal CGR1 allele was deleted by transformation with a CGR1 disruption cassette. The disruption cassette was constructed by PCR amplification of the kanamycin-resistance gene $\left(k a n^{r}\right)$ using plasmid pFA6-kanMX2 (Wach et al., 1994) as the template with primers containing $50 \mathrm{bp}$ CGR1-homologous sequences. The upstream primer was 5'-ACTGTCCATATTCATTGAAAGCAAAATAAAACATAACCAGGAAATCAGCTGAAGCTTCGTACGC-3' and the downstream primer was 5'-CTGTCTAGGGATGCCCTTATTTTCTCCTTGTCAGGACTTAATAATGCATAGGCCACTAGTGGATCTG-3' (sequences in italic are specific to pFA6-3HA-kanMX2). Following selection on G418 plates, the colonies were genotyped by PCR and deletion of the CGR1 ORF was confirmed by genomic Southern blot analysis, using radiolabelled probes specific for the CGR 1 and $k a n^{\mathrm{r}}$ genes. Down-regulation of the tetO-CYC1 promoter in pDA361 was accomplished by supplementing the medium with $2 \mu \mathrm{g} \mathrm{ml}^{-1}$ of the tetracycline analogue doxycycline, as described by Gari et al. (1997).

Pulse-chase analysis of rRNA processing. For the [methyl$\left.{ }^{3} \mathrm{H}\right]$ methionine pulse-chase experiments, wild-type and YDA110 cells were grown to a density of $(1-2) \times 10^{7}$ cells ml $^{-1}$ in methionine-free media at $25^{\circ} \mathrm{C}$. Wild-type cells containing pCM183 (Table 1) and YDA128 were grown to a density of $(2-4) \times 10^{7}$ cells $\mathrm{ml}^{-1}$ in methionine-free media at $25^{\circ} \mathrm{C}$. The cells were diluted into media containing $2 \mu \mathrm{g}$ doxycycline $\mathrm{ml}^{-1}$ and cultured for $29 \mathrm{~h}$. A total of $10^{8}$ cells was concentrated to a volume of $1 \mathrm{ml}$ and pulse labelled with $250 \mu \mathrm{Ci}(9 \cdot 25 \mathrm{MBq})$ [methyl- ${ }^{3} \mathrm{H}$ ] methionine for $2 \mathrm{~min}\left(70-85 \mathrm{Ci} \mathrm{mmol}^{-1}, 5 \mathrm{mCi}\right.$ $\mathrm{ml}^{-1}$, $185 \mathrm{MBq} \mathrm{ml}^{-1}$; Amersham-Pharmacia Biotech). For the zero time point, $250 \mu \mathrm{l}$ cells was transferred to a new tube, washed in $1 \mathrm{ml}$ ice-cold media and the cell pellet frozen on dry ice. Chase was initiated by adding unlabelled methionine to the culture at a concentration of $1 \mathrm{mg}$ methionine $\mathrm{ml}^{-1}$. At time points of 2,5 and $10 \mathrm{~min}$ of chase, $250 \mu \mathrm{l}$ cells were removed and processed as described above. RNA was isolated by the hot acid phenol method (Ausubel et al., 1997). A total of 20000 c.p.m. radioactivity was loaded per lane onto a $1.2 \%(\mathrm{w} / \mathrm{v})$ agarose-formaldehyde gel. RNA was transferred to a nylon membrane (Hybond- $\mathrm{N}^{+}$, Amersham-Pharmacia), UV-cross-linked and sprayed with $\mathrm{En}^{3}$ hance (NEN). The membrane was exposed to film for 1 day at $-80{ }^{\circ} \mathrm{C}$.

For $\left[5,6-{ }^{3} \mathrm{H}\right]$ uracil pulse-chase experiments, wild-type and YDA110 cells containing pRS306 (URA3 CEN) were grown to a density of $1 \times 10^{7}$ cells $\mathrm{ml}^{-1}$ in media lacking uracil at $25^{\circ} \mathrm{C}$. A total of $5 \times 10^{8}$ cells was concentrated to a volume of $6 \mathrm{ml}$ 
and labelled with $100 \mu \mathrm{Ci}(3 \cdot 7 \mathrm{MBq})\left[5,6-{ }^{3} \mathrm{H}\right]$ uracil (30$50 \mathrm{Ci} \mathrm{mmol}^{-1}, 1 \mathrm{mCi} \mathrm{ml}^{-1}, 37 \mathrm{MBq} \mathrm{ml}^{-1}$; NEN). After labelling for 3 and $6 \mathrm{~min}, 1 \mathrm{ml}$ culture was removed, centrifuged, supernatants removed, and cell pellets frozen. Chase was initiated by adding unlabelled uracil to a concentration of $20 \mathrm{mg}$ uracil $\mathrm{l}^{-1}$. At time points of 5, 10,30 and $60 \mathrm{~min}$ of chase (for the $6 \mathrm{~min}$ label), a $1 \mathrm{ml}$ sample was processed as described above and $5 \mu \mathrm{g}$ RNA from each time point was loaded onto a $8 \%$ polyacrylamide, $8 \mathrm{M}$ urea gel. RNA was transferred to Hybond- $\mathrm{N}^{+}$membranes by semi-dry electrophoresis (Owl Scientific) and visualized by fluorography as described above. The membrane was exposed to film for 15 days at $-80^{\circ} \mathrm{C}$.

Polysome profile analysis. Polysome profiles were performed as described by Kressler et al. (1997) with the following modifications. Cells were taken from the cultures used for the $\left[\right.$ methyl- $\left.{ }^{3} \mathrm{H}\right]$ methionine pulse-chase experiments described above, and the lysate ( $4 A_{260}$ units) was layered onto $10 \mathrm{ml}$ linear $7-49 \%$ sucrose gradients. Samples were centrifuged in a Beckman SW41Ti rotor for $2 \mathrm{~h}$ at 39000 r.p.m. at $4{ }^{\circ} \mathrm{C}$ (Beckman Instruments). A Beckman fraction recovery system was used to pass the gradients through a Pharmacia UV-1 monitor to measure $A_{254}$. Analysis of dissociated ribosomal subunits was performed as described by Kressler et al. (1997). Cell extracts were prepared in $50 \mathrm{mM}$ Tris $/ \mathrm{HCl}(\mathrm{pH} 7 \cdot 5)$, $50 \mathrm{mM} \mathrm{NaCl}, 1 \mathrm{mM}$ DTT, and 2 absorbance units at $260 \mathrm{~nm}$ were layered onto $10-30 \%$ sucrose gradients prepared in the same buffer and centrifuged as described above.

Subcellular localization of Nop1p and 5'-ITS1. Nop1 was localized with anti-Nop1 monoclonal antibodies as previously described (Moy \& Silver 1999). 5'-ITS1 rRNA was localized by fluorescence in situ hybridization as described by Amberg et al. (1992) with the following modifications. An oligonucleotide complementary to the first 50 bases of ITS1 rRNA, 5'-ATGCTCTTGCCAAAACAAAAAAATCCATTTTCAAAATTATTAAATTTCTT-3', was synthesized with the Cy3 fluorophore at its $5^{\prime}$ end (IDT). Samples were hybridized with this oligonucleotide at a concentration of $50 \mathrm{nM}$.

\section{RESULTS}

\section{Mutants of CGR1 are growth impaired}

We have previously reported that CGR 1 is essential in the YPH274 background (Sun et al., 2001a). To date, we have microdissected a total of 64 tetrads from a CGR1/cgr1s heterozygote constructed in the YPH274 strain, each indicating that spore viability segregates with the wild-type allele. A slow-growing $\operatorname{cgr} 1 \Delta$ mutant has recently been reported using meiotic segregation analysis by the yeast deletion project (Winzeler et al., 1999), suggesting that Cgr1p may be non-essential in some strains. As a first step to determine if Cgr1p has a role in ribosome synthesis in $S$. cerevisiae, we constructed two haploid mutants that were deficient in Cgr1p function: a conditional Cgr1p depletion mutant and a C-terminal $\operatorname{cgr} 1$ truncation mutant. The depletion strain, YDA128, was created by deleting the chromosomal CGR1 ORF in a haploid strain that contained a plasmid-borne CGR1 gene under the control of a tetracycline-repressible promoter (see Methods). Genomic Southern blot analysis of YDA128 showed homologous targeting of the CGR1 allele (data not shown). Northern blot analysis was used to confirm that YDA128

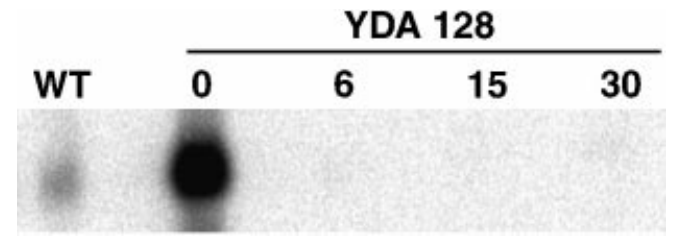

Fig. 2. Doxycycline-induced repression of CGR1 expression in YDA128. Wild-type cells (containing the empty pCM183 plasmid) and YDA128 cells were seeded at an $O_{600}$ of 0.1 in SD-trp medium and maintained in exponential phase by diluting into fresh medium whenever the culture density reached an $O D_{600}$ of 0.7 . RNA was isolated at the indicated times and analysed for CGR1 expression by Northern blot analysis. The first lane (WT) contains RNA from an exponentialphase culture of wild-type cells. The remaining four lanes contain equivalent amounts of RNA isolated from exponential cultures of YDA128 grown either in the absence of doxycycline (0) or in medium containing $2 \mu \mathrm{g}$ doxycycline $\mathrm{ml}^{-1}$ for 6,15 and $30 \mathrm{~h}$. Phosphorimager analysis of the SYBR-green-stained gel showed intact rRNA in all lanes, and the relative levels of the $18 S$ rRNA were used to normalize hybridization intensity for RNA loading.

cells treated with doxycycline were expressing levels of CGR1 that were below the levels seen in wild-type cells. In the absence of doxycycline, exponential cultures of YDA128 expressed 17-fold more CGR1 RNA than wildtype cells (Fig. 2, compare wild-type with the zero time point for YDA128). However, within $6 \mathrm{~h}$ of treatment with doxycycline, CGR1 expression was repressed (Fig. 2 ), falling over 10 -fold below the levels observed in exponentially growing wild-type cells. When overnight cultures of wild-type and YDA128 cells were diluted into fresh medium containing doxycycline, and maintained in exponential phase by diluting whenever the culture reached an $\mathrm{OD}_{600}$ of $0 \cdot 7$, the cultures initially grew with the same generation time of $2 \cdot 3 \mathrm{~h}$. However, after $12-15 \mathrm{~h}$ in doxycycline, the generation time of YDA128 was increased to $5.5 \mathrm{~h}$ (Fig. 3). Doxycycline had no effect on the growth rate of wild-type cells at the concentrations used in this experiment (data not shown). Since extended exposure of the Northern blot shown in Fig. 2 showed that some CGR1 expression remained in the doxycycline-treated YDA128 cells, this promoter was not completely repressed in the presence of doxycycline. However, the results indicate that wild-type levels of CGR $1 \mathrm{mRNA}$ are required for optimal growth, thus providing an opportunity to determine how reduced CGR1 mRNA affects ribosome synthesis.

A second mutant strain, YDA110, was constructed by introducing a stop codon into the chromosomal CGR1 gene, thereby truncating the expressed protein at amino acid 81. Homologous targeting of the CGR1 allele was confirmed by genomic Southern blot analysis (data not shown). This mutant was also growth impaired (generation time $3.8 \mathrm{~h}$ ), but to a lesser extent than doxycycline-treated YDA128 cells (generation time $5.5 \mathrm{~h}$ ), suggesting that the truncated protein has residual activity. These results indicate that a truncated Cgr1p is 


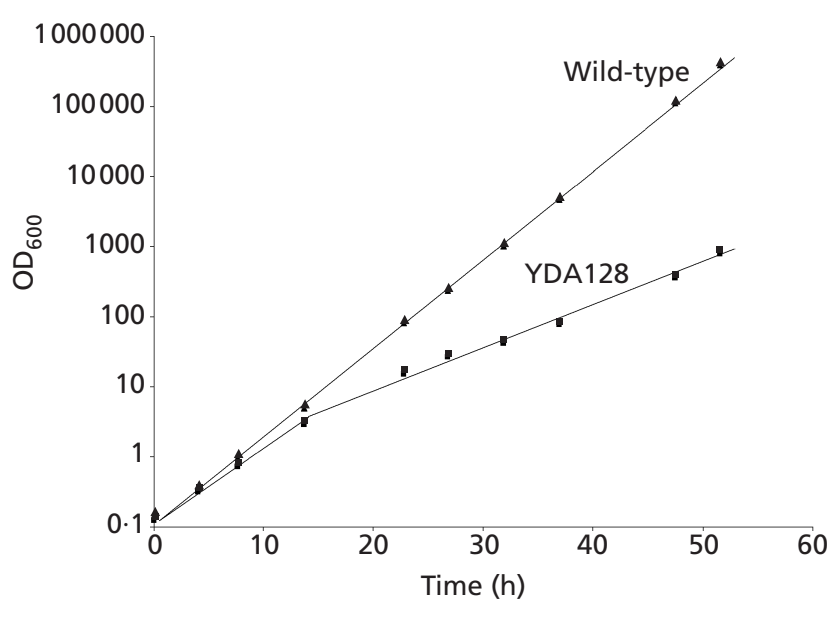

Fig. 3. Cgr1p deficiency impairs growth. Overnight cultures of wild-type and YDA128 cells were seeded into YPD medium containing $2 \mu \mathrm{g}$ doxycycline $\mathrm{ml}^{-1}$ and diluted whenever the culture attained an $\mathrm{OD}_{600}$ of 0.7 to maintain exponential growth. Wild-type: cry1 cells containing the empty pCM183 plasmid (Table 1).

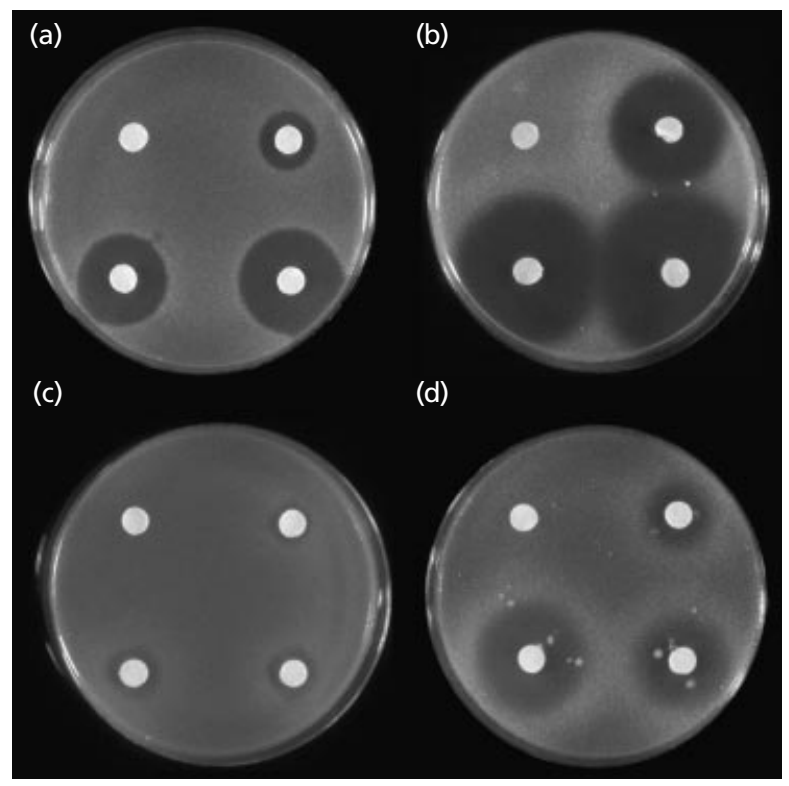

Fig. 4. Cells expressing a truncated Cgr1p show increased sensitivity to translational inhibitors. Filter paper circles containing $10 \mu \mathrm{l}$ of an antibiotic concentration were placed onto a YPD plate containing $1 \times 10^{7}$ wild-type (a and c) or YDA110 (b and d) cells. (a) and (b) contain hygromycin (top left, $0 \mathrm{mg} \mathrm{m}^{-1}$; top right, $50 \mathrm{mg} \mathrm{ml}^{-1}$; bottom left, $100 \mathrm{mg} \mathrm{ml}^{-1}$; bottom right, $250 \mathrm{mg} \mathrm{ml}^{-1}$ ). (c) and (d) contain paromomycin (top left, $0 \mathrm{mg} \mathrm{ml}^{-1}$; top right, $50 \mathrm{mg} \mathrm{ml}^{-1}$; bottom right, $200 \mathrm{mg} \mathrm{ml}^{-1}$; bottom left, $500 \mathrm{mg} \mathrm{ml}^{-1}$ ). Wild-type, Cry1.

insufficient to support optimal growth, thus providing an independent mutant in which to assess the consequences of impaired Cgr1p function on ribosome synthesis.
WT
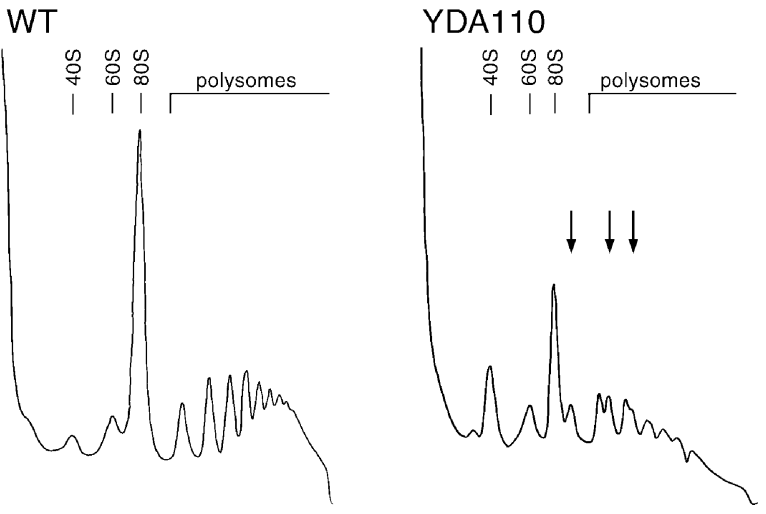

Fig. 5. Cgr1p is required for normal synthesis of 605 ribosomal subunits. Cells were harvested from exponential-phase cultures and polysome profiles were resolved in sucrose gradients. Peaks corresponding to free $40 \mathrm{~S}$ and $60 \mathrm{~S}$ subunits, $80 \mathrm{~S}$ couples and polysomes are indicated. Arrows indicate the presence of halfmers in YDA110 cells.

\section{cgr1 mutants are hypersensitive to translation inhibitors}

Yeast mutants deficient in ribosome assembly or function often display increased sensitivity to aminoglycoside antibiotics (Zanchin et al., 1997; Benard et al., 1998; Ho \& Johnson, 1999; Dresios et al., 2000). We have previously shown that a strain expressing CGR1 from a glucose-repressible promoter is hypersensitive to the aminoglycoside paromomycin under repressing conditions (Sun et al., 2001a). To determine whether the cgr1 truncation mutant also confers increased susceptibility to translational inhibitors, the sensitivity of YDA110 cells to paromomycin and hygromycin was examined. Glass filter discs containing various concentrations of each antibiotic were placed onto the surface of a plate of confluent cells and cultured for 4 days at $30{ }^{\circ} \mathrm{C}$. As shown by the zone of growth inhibition surrounding the filter paper discs, strain YDA110 was more sensitive to both of these antibiotics than wildtype cells (Fig. 4), indicating that inhibitors of translational fidelity synergize with loss of Cgr1 function to inhibit growth.

\section{cgr1 mutants are deficient in the synthesis of 605 ribosomal subunits}

To determine if Cgr1p has a role in ribosome synthesis, the polysome profile of each $\operatorname{cgr} 1$ mutant was analysed on sucrose density gradients and compared to that of wild-type cells. As shown in Fig. 5, wild-type cells showed the typical profile of $40 \mathrm{~S}$ and $60 \mathrm{~S}$ subunits, the $80 \mathrm{~S}$ monosome, and polysome peaks representing 2-8 ribosomes. By contrast, YDA110 cells showed a reduction in the level of the $60 \mathrm{~S}$ subunit relative to free $40 \mathrm{~S}$ subunits, a reduction in the level of the $80 \mathrm{~S}$ monosome peak, an overall decrease in the mean number of ribosomes in polysomes, and the appearance of halfmer polysomes (Fig. 5). Half-mer polysomes, evident as 
(a)

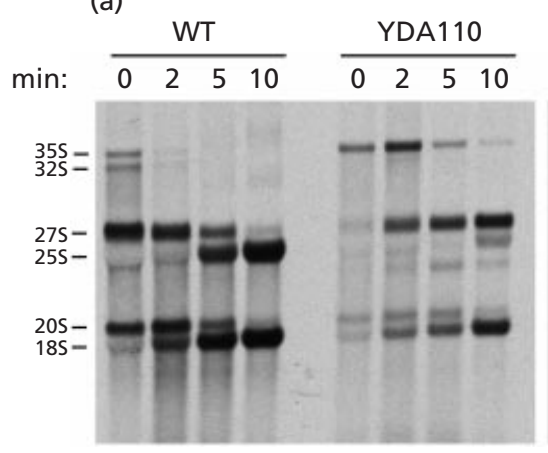

(b)
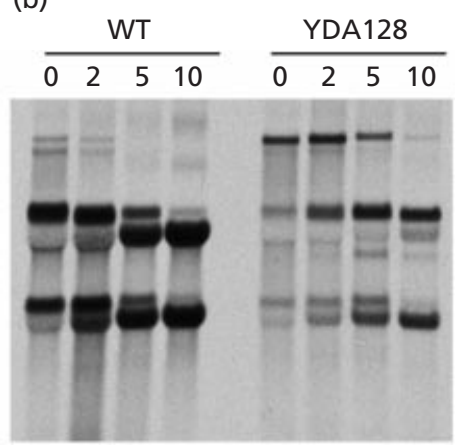

Fig. 6. Pulse-chase labelling indicates a role for Cgr1p in pre-rRNA processing. Cells were pulse-labelled with [methyl- ${ }^{3} \mathrm{H}$ ]methionine for $2 \mathrm{~min}$ and then chased with unlabelled methionine for 2, 5 and $10 \mathrm{~min}$. Total RNA was extracted, separated on an agaroseformaldehyde gel and visualized by fluorography following transfer to a nylon membrane. (a) Wild-type (Cry1) and YDA110 cells grown in YPD. (b) Wild-type (Cry1 cells containing $\mathrm{pCM} 183$ ) and YDA128 cells grown for $29 \mathrm{~h}$ in YPD containing $2 \mu \mathrm{g}$ doxycycline $\mathrm{ml}^{-1}$. The positions of the mature rRNAs and their precursors are indicated. small peaks following the $80 \mathrm{~S}$ and first two polysome peaks, represent $43 \mathrm{~S}$ pre-initiation complexes composed of mRNA, the 40S subunit and initiation factors (Helser et al., 1981). The reduction in the level of the $60 \mathrm{~S}$ subunit, and presence of half-mers, suggested a stoichiometric imbalance between $60 \mathrm{~S}$ and $40 \mathrm{~S}$ subunits. This was confirmed by examining the relative amounts of total 605 and $40 S$ subunits under conditions that cause dissociation of the subunits. A normal ratio of 60S: $40 \mathrm{~S}$ subunits of around 2 was observed for wildtype cells. By contrast, the ratio of $60 \mathrm{~S}: 40 \mathrm{~S}$ subunits in YDA110 cells was approximately equivalent, confirming a disruption in $60 \mathrm{~S}: 40 \mathrm{~S}$ stoichiometry (data not shown). YDA128 cells depleted of CGR1 by growth in doxycycline for $24 \mathrm{~h}$ showed the same polysome profile as YDA110 cells (data not shown), indicating that either Cgr1p truncation, or a decrease in the levels of the wildtype protein, adversely affects the synthesis of the $60 \mathrm{~S}$ subunit.

\section{Cgr1p is required for normal pre-rRNA processing}

The polysome profiles of the $\operatorname{cgr} 1$ mutant shown in Fig. 5 indicated that Cgr1p is required for the maintenance of normal 605 ribosome subunit levels. Since a decrease in the level of a ribosome subunit is often caused by a defect in pre-rRNA processing and/or assembly of ribosomal subunits (Kressler et al., 1999; Venema \& Tollervey, 1999), we examined the synthesis and processing of pre-rRNA in each of the mutants. The major pre-rRNA processing pathways in $S$. cerevisiae are depicted in Fig. 1. Since the $18 \mathrm{~S}$ and $25 \mathrm{~S}$ rRNAs are highly methylated, their synthesis and processing can be readily followed by metabolic labelling with $\left[\right.$ methyl- $\left.{ }^{3} \mathrm{H}\right]$ methionine (Warner, 1991). Exponentially growing cultures in medium lacking methionine were pulse-labelled for $2 \mathrm{~min}$ with [methyl- ${ }^{3} \mathrm{H}$ ]methionine and chased for 2, 5 and 10 min with an excess of cold methionine. Total RNA was extracted from the cells, fractionated by formaldehyde-agarose gel electrophoresis and analysed for the presence of pre-rRNA species as described in Methods. As expected, the wild-type 35S and $32 \mathrm{~S}$ precursors disappeared within $2 \mathrm{~min}$ of the chase (Fig. 6a), indicating normal and rapid processing to the $27 \mathrm{~S}$ and $20 \mathrm{~S}$ intermediates. After $5 \mathrm{~min}$ chasing, the majority of the label was present in the mature $25 \mathrm{~S}$ and $18 \mathrm{~S}$ rRNAs, and by 10 min only the mature rRNAs were evident (Fig. 6a). By contrast, the $27 \mathrm{~S}$ pre-rRNA accumulated in the YDA110 strain and only a small amount of this intermediate was processed into the $25 \mathrm{~S}$ rRNA, even after 10 min chasing (Fig. 6a). Consistent with this delay in $27 \mathrm{~S}$ pre-rRNA processing was a slight reduction in the steady-state levels of the mature $25 \mathrm{~S}$ rRNA (data not shown). The processing of the 35S pre-rRNA was also slightly delayed, but since there was no accumulation of the $20 \mathrm{~S}$ pre-rRNA, and the appearance of the $18 \mathrm{~S}$ rRNA occurred with the same kinetics as wild-type, we conclude that the truncated Cgr1 protein was interfering with processing of the $27 \mathrm{~S}$ rRNA.

To determine if the effect on 25S rRNA synthesis was due to a general loss of Cgr1 function or to an abnormal effect of the truncated protein, the same experiments were performed on cells depleted of Cgr1p. Exponential cultures of YDA128 grown in the presence of doxycycline for $29 \mathrm{~h}$ were pulse-chase labelled with [methyl$\left.{ }^{3} \mathrm{H}\right]$ methionine and analysed for processing of the $35 \mathrm{~S}$ pre-rRNA as described above. As shown in Fig. 6(b), wild-type cells containing the empty tetracycline-repressible plasmid processed the $35 \mathrm{~S}$ pre-rRNA with the same kinetics as wild-type cells, indicating that doxycycline treatment did not adversely affect pre-rRNA processing. By contrast, YDA128 cells depleted of Cgr1p showed the same defect in the processing of the $27 \mathrm{~S}$ prerRNA as YDA110 cells, with normal processing of the $20 \mathrm{~S}$ pre-rRNA (Fig. 6b). A small amount of the $23 \mathrm{~S}$ rRNA may be increased in YDA110 and YDA128 after 5 min chasing (Fig. 6a, b). The $23 \mathrm{~S}$ pre-rRNA is an unusual processing intermediate leading to the production of the $18 \mathrm{~S}$ rRNA and is generated by cleavages $A_{0}$ and $A_{3}$ (Russell \& Tollervey, 1992). This pathway is infrequently used in wild-type yeast, but increased levels of the $23 \mathrm{~S}$ rRNA have been associated with depletion of other proteins involved in pre-rRNA processing (Tollervey et al., 1991; Girard et al., 1992; Hong et al., 1997). Taken together, these results indicate that the primary defect associated with loss of Cgr1p function, either through protein truncation or depletion, is in the 


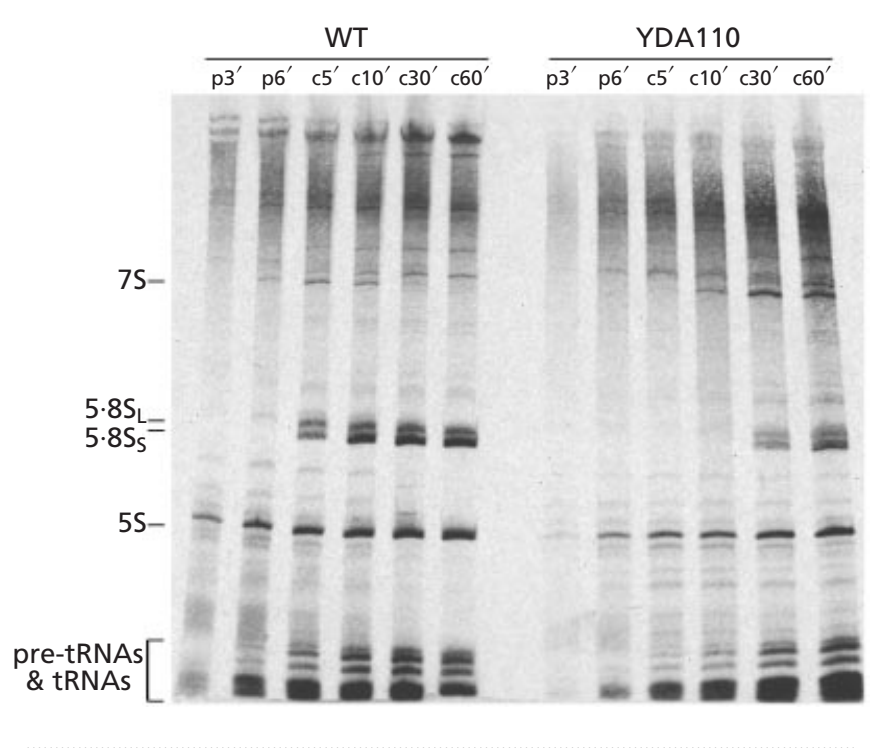

Fig. 7. Pulse-chase labelling of pre-rRNA processing in YDA110 using $\left[{ }^{3} \mathrm{H}\right]$ uracil. Wild-type and YDA110 cells were pulsed with $\left[{ }^{3} \mathrm{H}\right]$ uracil for $3 \mathrm{~min}\left(\mathrm{p}^{\prime}\right)$ or $6 \mathrm{~min}\left(\mathrm{p}^{\prime}\right)$, followed by a chase with unlabelled uracil for $5,10,30$ and $60 \mathrm{~min}$ (with the $6 \mathrm{~min}$ label). Total RNA was extracted, separated on a polyacrylamideurea gel and visualized by fluorography following transfer to a nylon membrane. The positions of the pre-rRNA, mature rRNAs and tRNAs are indicated.

formation of the $25 \mathrm{~S}$ rRNA from the $27 \mathrm{~S}$ pre-rRNA intermediate.

The defect in $27 \mathrm{~S}$ pre-rRNA processing in YDA110 and YDA128 predicted that the formation of the $5 \cdot 8 \mathrm{~S}$ rRNA should also be adversely affected (Fig. 1). We therefore examined $5 \cdot 8 \mathrm{~S}$ rRNA synthesis in YDA110 cells by pulse labelling with $\left[{ }^{3} \mathrm{H}\right]$ uracil for 3 or 6 min followed by a chase with an excess of cold uracil for 5, 10, 30 and $60 \mathrm{~min}$ (for the $6 \mathrm{~min}$ pulse). In wild-type cells, both forms of the $5.8 \mathrm{~S}$ RNA were evident within 5 min of chasing (Fig. 7), indicating a normal rate of processing. By comparison, the formation of the $5.8 \mathrm{~S}$ rRNA was delayed in YDA110 cells (Fig. 7), consistent with the defect in $27 \mathrm{~S}$ pre-rRNA processing that was observed in this strain (Fig. 6). The processing of the $7 \mathrm{~S}$ pre-rRNA was also delayed in YDA110 (Fig. 7), suggesting that Cgr1p may have a role in the processing of this intermediate into the mature $5.8 \mathrm{~S}$ rRNA. The $5 \mathrm{~S}$ rRNA is transcribed from a separate transcription unit by RNA polymerase III (Raué \& Planta, 1991) and although it forms a stable complex with rpL1, and is incorporated into the 60S subunit (Deshmukh et al., 1993), this experiment showed no major defects in 5S rRNA synthesis in YDA110 cells (Fig. 7).

\section{Cgr1p contributes to nucleolar compartmentalization}

Current evidence indicates that the nucleolar compartment is formed by the recruitment of processing factors by direct or indirect interactions with rDNA or the nascent RNAs (reviewed by Melèse \& Xue, 1995;

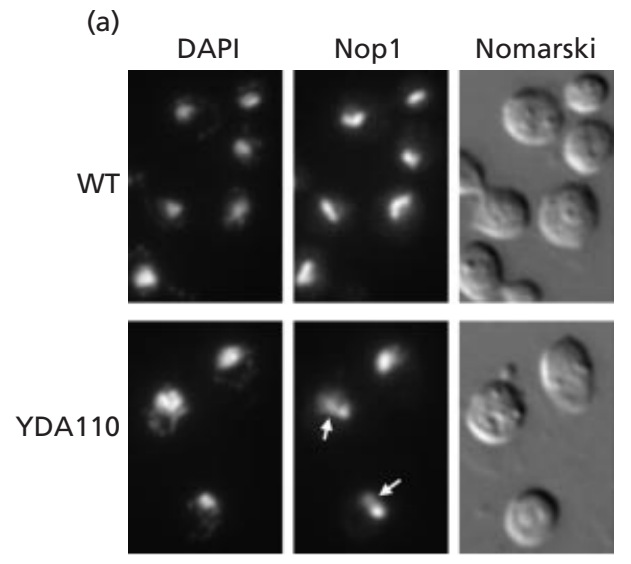

(b)

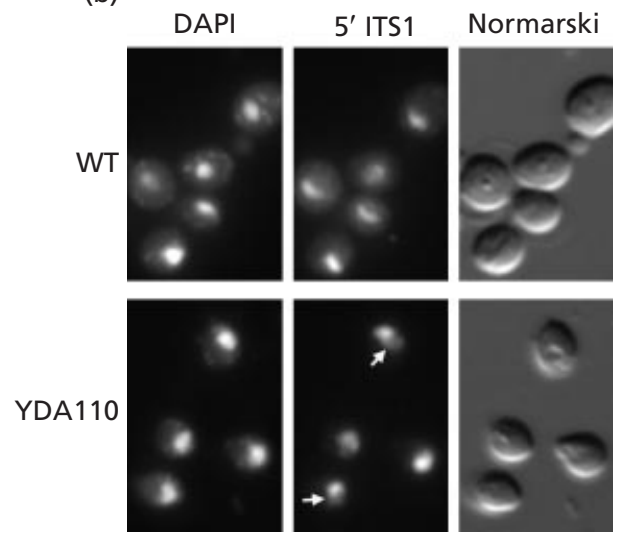

Fig. 8. Loss of Cgr1p function impairs nucleolar localization of Nop1p and 5'-ITS1. (a) Anti-Nop1p staining of wild-type and YDA110 cells shows increased levels of Nop1p in the nucleoplasm of YDA110 cells compared to wild-type (arrows). (b) Localization of 5'-ITS1 RNA by in situ hybridization of wildtype and YDA110 cells shows increased amounts of 5'-ITS1 in the nucleoplasm of YDA110 cells relative to wild-type (arrows). The DAPI-stained nucleus and Nomarski image for each figure is shown for comparison. Wild-type: Cry1.

Carmo-Fonseca et al., 2000). To determine whether Cgr1p has a role in maintaining the integrity of the nucleolar compartment, we examined the localization of the nucleolar protein Nop1p in the cgr1 truncation mutant. Nop1p is an essential nucleolar protein involved in pre-rRNA processing and ribosomal subunit assembly (Tollervey et al., 1993) and has been shown to colocalize with Cgr1p in the nucleolus (Sun et al., 2001a). In wild-type cells, the vast majority of Nop1p localized to the nucleolar region of the nucleus, with very little of the protein in the nucleoplasm (Fig. 8a). Although Nop1p was also found in the nucleolus in YDA110 cells, there was a notable increase in the amount that was present in the nucleoplasm (Fig. 8a, arrows), suggesting that the ability of Nop1p to accumulate within the nucleolus was partially impaired in this mutant.

To determine whether this impaired localization was specific to Nop1p, we examined another nucleolar 
marker, 5'-ITS1. In S. cerevisiae, the $20 \mathrm{~S}$ rRNA is assembled as part of the 43 pre-ribosome in the nucleolus prior to export to the cytoplasm. Once in the cytoplasm the $20 \mathrm{~S}$ rRNA is cleaved by an endonuclease to the mature 18S rRNA and the released 5'-ITS1 spacer sequence is rapidly degraded by Xrn1p (Stevens et al., 1991). The location pattern of the $5^{\prime}$-ITS1 RNA is an indicator of the assembly and nuclear export of the small ribosomal subunit and $5^{\prime}$-ITS1 can be detected by in situ hybridization with a Cy3-labelled 5'-ITS1 probe (Moy \& Silver, 1999). In wild-type cells, the majority of the $5^{\prime}$-ITS1 RNA was found in the nucleolar crescent (Fig. 8b). By contrast, YDA110 cells showed a relative increase in the amount of $5^{\prime}$-ITS1 RNA in the nucleoplasm (Fig. 8b, arrows). Taken together, these results suggest that loss of Cgr1p function adversely affects the compartmentalization of these nucleolar constituents.

\section{DISCUSSION}

Although rDNA transcription, rRNA processing and ribosome assembly are the best characterized functions of the nucleolus, there is increasing appreciation for this organelle as a site for other cellular activities. The nucleolus has been implicated in the nuclear export of mRNAs (Kadowaki et al., 1994; Schneiter et al., 1995; Tani et al., 1995), in the processing of tRNA (Bertrand et al., 1998) and in the synthesis of the RNA components for the signal recognition particle and the enzyme telomerase (Fang \& Cech, 1995; Jacobson \& Pederson, 1998; Grosshans et al., 2001). Furthermore, at least two yeast cell cycle regulatory proteins are sequestered in the nucleolus away from their known targets, thereby restricting functional activity to specific points in the cell cycle (San-Segundo \& Roeder, 1999; Shou et al., 1999; Visintin et al., 1999). Finally, recent evidence has shown that some yeast nucleolar proteins are potent regulators of the pace of cellular senescence and in the silencing of rDNA (Gotta et al., 1997; Kennedy et al., 1997; Kaeberlein et al., 1999; Gartenberg, 2000). The nucleolus is thus a plurifunctional organelle and the proteins that localize to this compartment may have functional activities outside the nucleolus.

To investigate the possibility that the nucleolar localization of $S$. cerevisiae Cgr1p is due to its role in yeast ribosome synthesis, we have examined mutants deficient in Cgr1 function for abnormalities in ribosomal subunits and pre-rRNA processing. Each of the two $\operatorname{cgr} 1$ mutants generated for this study was deficient in the steady-state levels of 605 ribosome subunits, resulting in abnormally high levels of the $40 S$ subunit and an increase in half-mer polysomes. Similar profiles have been described for mutants defective in components required for pre-rRNA processing or $60 \mathrm{~S}$ subunit assembly (Ripmaster et al., 1992; Hong et al., 1997; de la Cruz et al., 1998a ; Basu et al., 2001), suggesting that Cgr1p is also involved in this pathway.

Analysis of pre-rRNA processing showed that the deficit in $60 \mathrm{~S}$ subunits in the $\operatorname{cgr} 1$ mutants was attributable to a primary defect in $27 \mathrm{~S}$ pre-rRNA processing, thereby affecting the synthesis of the mature $25 \mathrm{~S}$ and $5 \cdot 8 \mathrm{~S}$ rRNAs. The role of Cgr1p in 25S/5.8S rRNA synthesis appears to be specific because synthesis of the $18 \mathrm{~S}$ rRNA and $5 \mathrm{~S}$ rRNAs was unaffected in either of the cgr1 mutants. This places Cgr1p in a category of proteins that influence the production of the 25S rRNA (Moritz et al., 1991; Russell \& Tollervey, 1992; Deshmukh et al., 1993; Berges et al., 1994; Fabian \& Hopper 1997; Hong et al., 1997; Basu et al., 2001). However, in addition to the major effects on the synthesis of the $25 \mathrm{~S} / 5.8 \mathrm{~S}$ rRNAs, we also observed delayed processing of the $35 \mathrm{~S}$ pre-rRNA and accumulation of the $7 \mathrm{~S}$ intermediate. This suggests that Cgr1p may influence several steps in the pathway to ribosome synthesis, for which there is precedence among factors involved in pre-rRNA processing and ribosome assembly (Kressler et al., 1999), although it is also conceivable that the effect is indirect. It has been suggested that a delay in processing of $35 \mathrm{~S}$ pre-rRNA may be a consequence of a negative feedback mechanism to slow production of the $18 \mathrm{~S}$ rRNA whenever the formation of the 25S $/ 5.8 \mathrm{~S}$ rRNA is inhibited (Zanchin et al., 1997; de la Cruz et al., 1998b). However, the delay in $35 \mathrm{~S}$ pre-rRNA processing observed in these $\operatorname{cgr} 1$ mutants had little effect on the overall synthesis of the 18S rRNA.

The phenotype of the cgr1 mutants resembles the phenotype described for a mutant of Dob1p, a putative ATP-dependent RNA helicase. Similar to cgr1 mutants, the dob1 mutant has a defect in the synthesis of the $5.8 \mathrm{~S}$ and $25 \mathrm{~S}$ rRNAs, a reduction in $60 \mathrm{~S}$ subunits and an increase in 7S rRNA (de la Cruz, 1998b). The processing of the $7 \mathrm{~S}$ rRNA involves the activity of a complex of $3^{\prime} \rightarrow 5^{\prime}$ exonucleases called the exosome, and Dob1p acts as a cofactor for this complex (Allmang et al., 1999). The similarity between the dob1 and $\operatorname{cgr} 1$ mutants raises the possibility that Cgr1p has a direct or indirect effect on the activity of the exosome.

The yeast nucleolus occupies a crescent-shaped region of the nucleus that is approximately one-third of the total nuclear volume (Warner, 1982). The assembly of the nucleolus is thought to involve the recruitment of various processing factors through direct or indirect interactions with rDNA, nascent rRNAs, or nucleolar proteins that already reside in the nucleolus (Melèse \& Xue, 1995; Carmo-Fonseca, 2000). For example, Net1p preferentially binds to rDNA and is required for the recruitment of the silencing protein $\operatorname{Sir} 2 \mathrm{p}$ into the nucleolus (Straight et al., 1999). In net1s cells, Nop1p redistributes over the nucleus, suggesting that Net1p is required to maintain the integrity of the nucleolar compartment. Our results indicate that cells deficient in Cgr1p are unable to retain all Nop1p and 5'-ITS1 in the nucleolar region and this would also be consistent with a role for Cgr1p in nucleolar integrity.

In contrast to highly conserved nucleolar proteins such as Nop1p (Tollervey et al., 1991, 1993), there are no clear homologues of Cgr1p in higher eukaryotes, including Drosophila melanogaster and Caenorhabditis elegans, raising the possibility that Cgr1p is either fungal 
specific or highly divergent in metazoan species. If the $A$. fumigatus orthologue of Cgr1p proves to be essential for the growth of A. fumigatus, its apparent divergence in higher eukaryotes would make it an attractive antifungal target. Further understanding of the role for Cgr1p in fungal ribosome synthesis awaits mechanistic detail on how this protein contributes to pre-rRNA processing.

\section{ACKNOWLEDGEMENTS}

Supported in part by grants from the American Cancer Society (Ohio) to D.S.A., NIAID to J.C.R., NCI to T.M. and NIH to P.A.S. We thank Jay Card for assistance with photography.

\section{REFERENCES}

Allmang, C., Kufel, J., Chanfreau, G., Mitchell, P., Petfalski, E. \& Tollervey, D. (1999). Functions of the exosome in rRNA, snoRNA and snRNA synthesis. EMBO J 18, 5399-5410.

Amberg, D. C., Goldstein, A. L. \& Cole, C. N. (1992). Isolation and characterization of RAT1: an essential gene of Saccharomyces cerevisiae required for the efficient nucleocytoplasmic trafficking of mRNA. Genes Dev 6, 1173-1189.

Ausubel, F. M., Brent, R., Kingston, R. E., Moore, D. D., Seidman, J. G., Smith, J. A. \& Struhl, K. (1997). Current Protocols in Molecular Biology. New York: Wiley.

Basu, U., Si, K., Warner, J. R. \& Maitra, U. (2001). The Saccharomyces cerevisiae TIF6 gene encoding translation initiation factor 6 is required for $60 \mathrm{~S}$ ribosomal subunit biogenesis. Mol Cell Biol 75, 1453-1462.

Benard, L., Carroll, K., Valle, R. C. \& Wickner, R. B. (1998). Ski6p is a homolog of RNA-processing enzymes that affects translation of non-poly(A) mRNAs and $60 \mathrm{~S}$ ribosomal subunit biogenesis. $\mathrm{Mol}$ Cell Biol 18, 2688-2696.

Berges, T., Petfalski, E., Tollervey, D. \& Hurt, E. C. (1994). Synthetic lethality with fibrillarin identifies NOP77p, a nucleolar protein required for pre-rRNA processing and modification. EMBO J 13, 3136-3148.

Bertrand, E., Houser-Scott, F., Kendall, A., Singer, R. H. \& Engelke, D. R. (1998). Nucleolar localization of early tRNA processing. Genes Dev 12, 2463-2468.

Boettner, D., Huebner, N., Rhodes, J. C. \& Askew, D. S. (2001). Molecular cloning of AfcgrA, the Aspergillus fumigatus ortholog of a conserved fungal nucleolar protein. Med Mycol 39, 517-521.

Burke, D., Dawson, D. \& Stearns, T. (editors) (2000). Methods in Yeast Genetics, pp. 171-181. Cold Spring Harbor, NY: Cold Spring Harbor Laboratory.

Carmo-Fonseca, M., Mendes-Soares, L. \& Campos, I. (2000). To be or not to be in the nucleolus. Nat Cell Biol 2, E107-E112.

de la Cruz, J., Kressler, D., Rojo, M., Tollervey, D. \& Linder, P. (1998a). Spb4p, an essential putative RNA helicase, is required for a late step in the assembly of $60 \mathrm{~S}$ ribosomal subunits in Saccharomyces cerevisiae. RNA 4, 1268-1281.

de la Cruz, J., Kressler, D., Tollervey, D. \& Linder, P. (1998b). Dob1p (Mtr4p) is a putative ATP-dependent RNA helicase required for the 3' end formation of 5.8S rRNA in Saccharomyces cerevisiae. EMBO J 4, 1128-1140.

Deshmukh, M., Tsay, Y. F., Paulovich, A. G. \& Woolford, J. L., Jr (1993). Yeast ribosomal protein L1 is required for the stability of newly synthesized 5S rRNA and the assembly of $60 \mathrm{~S}$ ribosomal subunits. Mol Cell Biol 13, 2835-2845.

Dresios, J., Derkatch, I. L., Liebman, S. W. \& Synetos, D. (2000).
Yeast ribosomal protein L24 affects the kinetics of protein synthesis and ribosomal protein L39 improves translational accuracy, while mutants lacking both remain viable. Biochemistry 39, 7236-7244.

Fabian, G. R. \& Hopper, A. K. (1987). RRP1, a Saccharomyces cerevisiae gene affecting rRNA processing and production of mature ribosomal subunits. J Bacteriol 169, 1571-1578.

Fang, G. \& Cech, T. R. (1995). Telomerase RNA localized in the replication band and spherical subnuclear organelles in hypotrichous ciliates. J Cell Biol 130, 243-253.

Gari, E., Piedrafita, L., Aldea, M. \& Herrero, E. (1997). A set of vectors with a tetracycline-regulatable promoter system for modulated gene expression in Saccharomyces cerevisiae. Yeast 13, 837-848.

Gartenberg, M. R. (2000). The Sir proteins of Saccharomyces cerevisiae: mediators of transcriptional silencing and much more. Curr Opin Microbiol 3, 132-137.

Girard, J. P., Lehtonen, H., Caizergues-Ferrer, M., Amalric, F., Tollervey, D. \& Lapeyre, B. (1992). GAR1 is an essential small nucleolar RNP protein required for pre-rRNA processing in yeast. EMBO J 11, 673-682.

Gotta, M., Strahl-Bolsinger, S., Renauld, H., Laroche, T., Kennedy, B. K., Grunstein, M. \& Gasser, S. M. (1997). Localization of Sir2p: the nucleolus as a compartment for silent information regulators. EMBO J 16, 3243-3255.

Grosshans, H., Deinert, K., Hurt, E. \& Simos, G. (2001). Biogenesis of the signal recognition particle (SRP) involves import of SRP proteins into the nucleolus, assembly with the SRP-RNA and Xpo1p-mediated export. J Cell Biol 153, 745-762.

Helser, T. L., Baan, R. A. \& Dahlberg, A. E. (1981). Characterization of a $40 S$ ribosomal subunit complex in polyribosomes of Saccharomyces cerevisiae treated with cycloheximide. Mol Cell Biol 1, 51-57.

Ho, J. H.-N. \& Johnson, A. W. (1999). NMD3 encodes an essential cytoplasmic protein required for stable 605 ribosomal subunits in Saccharomyces cerevisiae. Mol Cell Biol 19, 2389-2399.

Hong, B., Brockenbrough, S., Wu, P. \& Aris, J. P. (1997). Nop2p is required for pre-rRNA processing and $60 \mathrm{~S}$ ribosome subunit synthesis in yeast. Mol Cell Biol 17, 378-388.

Jacobson, M. R. \& Pederson, T. (1998). Localization of signal recognition particle RNA in the nucleolus of mammalian cells. Proc Natl Acad Sci U S A 95, 7981-7986.

Kadowaki, T., Hitomi, M., Chen, S. \& Tartakoff, A. (1994). Nuclear mRNA accumulation causes nucleolar fragmentation in yeast mtr2 mutant. Mol Biol Cell 5, 1253-1263.

Kaeberlein, M., McVey, M. \& Guarente, L. (1999). The SIR2/3/4 complex and SIR2 alone promote longevity in Saccharomyces cerevisiae by two different mechanisms. Genes Dev 13, 2570-2580.

Kennedy, B. K., Gotta, M., Sinclair, D. A. \& 7 other authors (1997). Redistribution of silencing proteins from telomeres to the nucleolus is associated with extension of life span in S. cerevisiae. Cell 89, 381-391.

Kressler, D., de la Cruz, J., Rojo, M. \& Linder, P. (1997). Fal1p is an essential DEAD-box protein involved in 40S-ribosomal-subunit biogenesis in Saccharomyces cerevisiae. Mol Cell Biol 17, 7283-7294.

Kressler, D., Linder, P. \& de la Cruz, J. (1999). Protein trans-acting factors involved in ribosome biogenesis in Saccharomyces cerevisiae. Mol Cell Biol 19, 7897-7912.

Li, J., Witte, D. P., Van Dyke, T. \& Askew, D. S. (1997). Expression of the putative protooncogene His-1 in normal and neoplastic tissues. Am J Pathol 150, 1297-1305. 
Melèse, T. \& Xue, Z. (1995). The nucleolus: an organelle formed by the act of building a ribosome. Curr Opin Cell Biol 7, 319-324.

Moritz, M., Pulaski, B. A. \& Woolford, J. L., Jr (1991). Assembly of $60 \mathrm{~S}$ ribosomal subunits is perturbed in temperature-sensitive yeast mutants defective in ribosomal protein L16. Mol Cell Biol 11, 5681-5692.

Moy, T. I. \& Silver, P.A. (1999). Nuclear export of the small ribosomal subunit requires the Ran-GTPase cycle and certain nucleoporins. Genes Dev 13, 2118-2133.

Nomura, M. (1999). Regulation of ribosome biosynthesis in Escherichia coli and Saccharomyces cerevisiae: diversity and common principles. J Bacteriol 181, 6857-6864.

Planta, R. J. (1997). Regulation of ribosome synthesis in yeast. Yeast 13, 1505-1518.

Raué, H. A. \& Planta, R. J. (1991). Ribosome biogenesis in yeast. Prog Nucleic Acid Res Mol Biol 41, 81-129.

Ripmaster, T. L., Vaughn, G. P. \& Woolford, J. L., Jr (1992). A putative ATP-dependent RNA helicase involved in Saccharomyces cerevisiae ribosome assembly. Proc Natl Acad Sci U S A 89, 11131-11135.

Russell, I. D. \& Tollervey, D. (1992). NOP3 is an essential yeast protein which is required for pre-rRNA processing. J Cell Biol 119, 737-747.

San-Segundo, P. A. \& Roeder, G. S. (1999). Pch2 links chromatin silencing to meiotic checkpoint control. Cell 97, 313-324.

Scheer, U. \& Weisenberger, D. (1994). The nucleolus. Curr Opin Cell Biol 6, 354-359.

Schneiter, R., Kadowaki, T. \& Tartakoff, A. M. (1995). mRNA transport in yeast: time to reinvestigate the functions of the nucleolus. Mol Biol Cell 6, 357-370.

Shaw, P. J. \& Jordan, E. G. (1995). The nucleolus. Annu Rev Cell Dev Biol 11, 93-121.

Shou, W., Seol, J. H., Shevchenko, A. \& 7 other authors (1999). Exit from mitosis is triggered by Tem1-dependent release of the protein phosphatase Cdc14 from nucleolar RENT complex. Cell 97, 233-244.

Stevens, A., Hsu, C. L., Isham, K. R. \& Larimer, F. W. (1991). Fragments of the internal transcribed spacer 1 of pre-rRNA accumulate in Saccharomyces cerevisiae lacking 5'-3' exoribonuclease 1. J Bacteriol 173, 7024-7028.

Straight, A., Shou, W., Dowd, G., Turck, C. W., Deshaies, R. J., Johnson, A. D. \& Moazed, D. (1999). Net1, a Sir2-associated nucleolar protein required for rDNA silencing and nucleolar integrity. Cell 97, 245-256.

Sun, J., McFarland, M., Boettner, D., Panepinto, J., Rhodes, J. C. \&
Askew, D. S. (2001a). Cgr1p, a novel nucleolar protein encoded by Saccharomyces cerevisiae orf YGL0292w. Curr Microbiol 42, 65-69.

Sun, J., Boettner, D., Huebner, N., Rhodes, J. C. \& Askew, D. S. (2001b). Molecular cloning of $\operatorname{cgr} A$, the gene encoding the Aspergillus nidulans ortholog of Saccharomyces cerevisiae Cgr1p. Curr Microbiol 42, 403-407.

Tani, T., Derby, R. J., Hiraoka, Y. \& Spector, D. L. (1995). Nucleolar accumulation of poly $(\mathrm{A})^{+}$RNA in heat-shocked yeast cells: implication of nucleolar involvement in mRNA transport. Mol Biol Cell 6, 1515-1534.

Tollervey, D., Lehtonen, H., Carmo, F. M. \& Hurt, E. C. (1991). The small nucleolar RNP protein NOP1 (fibrillarin) is required for pre-rRNA processing in yeast. EMBO J 10, 573-583.

Tollervey, D., Lehtonen, H., Jansen, R., Kern, H. \& Hurt, E. C. (1993). Temperature-sensitive mutations demonstrate roles for yeast fibrillarin in pre-rRNA processing, pre-rRNA methylation, and ribosome assembly. Cell 72, 443-457.

Venema, J. \& Tollervey, D. (1999). Ribosome synthesis in Saccharomyces cerevisiae. Annu Rev Genet 33, 261-311.

Visintin, R., Hwang, E. S. \& Amon, A. (1999). Cfi1 prevents premature exit from mitosis by anchoring Cdc14 phosphatase in the nucleolus. Nature 398, 818-823.

Wach, A., Brachat, A., Pohlmann, R. \& Philippsen, P. (1994). New heterologous modules for classical or PCR-based gene disruptions in Saccharomyces cerevisiae. Yeast 10, 1793-1808.

Warner, J. R. (1982). The yeast ribosome: structure, function, and synthesis. In The Molecular Biology of the Yeast Saccharomyces: Metabolism and Gene Expression, pp. 529-561. Edited by J. N. Strathern, E. W. Jones \& J. R. Broach. Cold Spring Harbor, NY: Cold Spring Harbor Laboratory.

Warner, J. R. (1991). Labeling of RNA and phosphoproteins in Saccharomyces cerevisiae. Methods Enzymol 194, 423-427.

Warner, J. R. (1999). The economics of ribosome biosynthesis in yeast. Trends Biochem Sci 24, 437-440.

Winzeler, E. A., Shoemaker D. D., Astromoff, A. \& 49 other authors (1999). Functional characterization of the $S$. cerevisiae genome by gene deletion and parallel analysis. Science 285, 901-906.

Zanchin, N. I., Roberts, P., de Silva, A., Sherman, F. \& Goldfarb, D. S. (1997). Saccharomyces cerevisiae Nip7p is required for efficient 605 ribosome subunit biogenesis. Mol Cell Biol 17, 5001-5015.

Received 6 September 2001; revised 22 October 2001; accepted 3 December 2001. 